\title{
ANALISIS FAKTOR-FAKTOR YANG MEMPENGARUHI MINAT BELI KONSUMEN MOTOR HONDA PADA \\ PT. TUNAS MOTOR PRATAMA DI BANDAR LAMPUNG
}

\section{ANALYSIS OF FACTORS AFFECTING BUYING INTEREST HONDA MOTORCYCLE AT PT.TUNAS MOTOR PRATAMA IN BANDAR LAMPUNG}

\author{
Oleh: \\ Melan Susanty Purnamasari \\ Yogi Aryanto \\ Program Studi Administrasi Bisnis Universitas Tulang Bawang - Lampung \\ E-mail: meilan.susanty@gmail.com
}

\begin{abstract}
Interest is one of the psychological aspects that has a considerable influence on behavior and interest is also a source of motivation that will direct a person to do what they do. In the general Indonesian dictionary, interest is liking (the inclination of the heart) to something of concern and desire. Dewa Ketut Sukardi defines interest as a positive attitude or feeling towards activities, people, experiences and objects. This research was conducted with the aim to determine the effect of product quality and promotion on purchasing decisions with purchase intention as an intervening variable, and the source is from consumers who purchase Honda motorbikes at PT. Tunas Motor Pratama. The form of observations made in this study is a survey form. The survey was conducted to obtain the facts of the existing symptoms and to look for them factually, in this study data were collected from respondents using a questionnaire. The data used in this study are primary data. The results obtained are in the form of products (X1) have a positive and significant effect on customer satisfaction. If the product warranty is good, the quality of the product is good and the products sold are complete / varied, then customer satisfaction will increase and vice versa, price (X2) has a positive but insignificant effect on customer satisfaction. If the price is more competitive, there are discounts for consumers, and the price is in accordance with the quality of the product being sold, the consumer's satisfaction increases and vice versa, and promotion (X3) affects purchase interest. This means that promotions that have been carried out have an effect on consumers to increase buying interest. If the promotion carried out by producers is directed, it will increase buying interest.
\end{abstract}

Keywords: interest, price, product quality, promotion, purchase decision.

\begin{abstract}
ABSTRAK
Minat merupakan salah satu aspek psikologis yang mempunyai pengaruh cukup besar terhadap perilaku dan minat juga merupakan sumber motivasi yang akan mengarahkan seseorang dalam
\end{abstract}


melakukan apa yang mereka lakukan. Dalam kamus umum Bahasa Indonesia, minat adalah kesukaan (kecenderungan hati) kepada sesuatu perhatian dan keinginan. Dewa ketut sukardi mengartikan minat adalah suatu sikap atau perasaan yang positif terhadap sesuatu aktifitas, orang, pengalaman dan benda-benda. Penelitian ini dilakukan dengan tujuan untuk mengetahui pengaruh kualitas produk dan promosi terhadap keputusan pembelian dengan minat beli sebagai variabel intervening, dan sumber tersebut dari konsumen yang melakukan pembelian motor Honda di PT. Tunas Motor Pratama. Bentuk pengamatan yang dilakukan dalam penelitian ini adalah bentuk survei. Survei dilakukan untuk memperoleh fakta-fakta dari gejala yang ada dan mecari secara faktual, dalam penelitian ini data dikumpulkan dari responden dengan menggunakan kuesioner. Data yang digunakan dalam penelitian ini adalah data primer. Hasil penelitian yang diperoleh yaitu berupa produk (X1) berpengaruh secara positif dan signifikan terhadap kepuasan konsumen. Jika garansi produk baik, kualitas produk baik dan produk yang dijual lengkap/beragam maka kepuasan konsumen akan naik dan sebaliknya, harga (X2) berpengaruh secara positif namun tidak signifikan terhadap kepuasan konsumen. Jika harga semakin bersaing, ada pemberian potongan harga kepada konsumen, dan harga sesuai dengan kualitas produk yang dijual maka kepuasan konsumen semakin meningkat dan sebaliknya serta promosi (X3) berpengaruh terhadap minat beli. Hal ini berarti promosi yang telah dilakukan berpengaruh terhadap konsumen untuk meningkatkan minat beli. Jika promosi yang dilakukan produsen terarah maka akan meningkatkan minat beli.

Kata kunci: harga, minat, keputusan pembelian, kualitas produk, promosi.

\section{PENDAHULUAN}

\subsection{Latar Belakang}

Seiring berkembangnya zaman kebutuhan terhadap kendaraan semakin meningkat, karena kendaraan sangat dibutuhkan untuk membantu manusia dalam melakukan aktifitas sehari-hari. Hal ini menyebabkan permintaan terhadap kendaraan semakin meningkat, salah satunya produk pabrikan Honda yang cukup banyak diminati oleh masyarakat di Indonesia. Semakin berkembangnya teknologi dan informasi saat ini, kemampuan perusahaan dituntut untuk lebih cermat dalam persaingan bisnis. Jika perusahaan ingin tetap eksis dalam persaingan, maka perusahaan harus memperhatikan salah satu fungsi pokoknya yaitu pemasaran. Fenomena persaingan di era globalisasi akan semakin mengarahkan sistem perekonomian negara manapun ke mekanisme pasar yang pada akhirnya memposisikan pemasar untuk selalu mengembangkan dan merebut pangsa pasar. Dalam melaksanakan pemasaran yang baik, produsen harus mengetahui dahulu apa yang menjadi kebutuhan dan keinginan konsumen, sehingga produk yang ditawarkan akan sesuai dengan permintaan konsumen. Selain itu dalam pemasaran tidak lepas dari faktor promosi, karena dengan promosi yang baik dan tepat sasaran konsumen akan berminat dan melakukan keputusan pembelian.

\subsection{Identifikasi Masalah}

Berdasarkan latar belakang tersebut maka permasalahan dalam penelitian ini dapat diidentifikasi sebagai berikut:

1. Tingginya persaingan dalam bisnis yang sama dikota Bandar Lampung.

2. Promosi yang dilakukan kurang optimal.

3. Adanya presepsi bahwa harga kurang bersaing.

4. Pelayanan yang kurang maksimal. 


\subsection{Pembatasan Masalah}

Berdasarkan latar belakang masalah dan identifikasi masalah yang ada di PT. Tunas Motor Pratama maka batasan masalah dalam penelitian ini adalah sebagai berikut :

1. Pengaruh masing masing variabel tentang faktor yang mempengaruhi minat beli konsumen : produk, harga, promosi terhadap kepuasan konsumen di PT. Tunas Motor Pratama.

2. Pengaruh variabel tentang faktor yang mempengaruhi minat beli konsumen : produk, harga, promosi secara bersama sama terhadap kepuasan konsumen di PT.Tunas Motor Pratama.

\subsection{Rumusan Masalah}

Berdasarkan latar belakang yang telah diuraikan di atas permasalah yang di hadapi PT. Tunas Motor Pratama adalah:

1. Apakah harga berpengaruh terhadap minat beli PT. Tunas Motor Pratama?

2. Apakah kualitas produk berpengaruh terhadap minat beli PT. Tunas Motor Pratama?

3. Apakah promosi berpengaruh secara langsung terhadap keputusan pembelian melalui minat beli PT. Tunas Motor Pratama?

\subsection{Tujuan Penelitian}

Berdasarkan latar belakang dan rumusan masalah, maka penelitian ini bertujuan :

1. Untuk mengetahui adanya pengaruh kualitas produk terhadap minat beli PT. Tunas Motor Pratama.

2. Untuk mengetahui adanya pengaruh harga terhadap keputusan pembelian PT. Tunas Motor Pratama.

3. Untuk mengetahui adanya pengaruh promosi terhadap keputusan pembelian PT. Tunas Motor Pratama. keputusan pembelian melalui minat beli PT. Tunas Motor Pratama.

\section{LANDASAN TEORI}

\subsection{Minat Beli Konsumen}

Minat merupakan salah satu aspek psikologis yang mempunyai pengaruh cukup besar terhadap perilaku dan minat juga merupakan sumber motivasi yang akan mengarahkan seseorang dalam melakukan apa yang mereka lakukan. Dalam kamus umum Bahasa Indonesia, minat adalah kesukaan (kecenderungan hati) kepada sesuatu perhatian dan keinginan. Dewa Ketut Sukardi mengartikan minat adalah suatu sikap atau perasaan yang positif terhadap sesuatu aktifitas, orang, pengalaman dan benda-benda.

Menurut Bimo Walgito menjelaskan minat adalah suatu keadaan dimana seseorang mempunyai perhatian terhadap sesuatu dan disertai keinginan untuk mengetahui dan mempelajari maupun membuktikan lebih lanjut. Minat sebagai aspek kejiwaan bukan hanya meSwarnai perilaku seseorang untuk melakukan aktifitas yang menyebabkan seseorang merasa tertarik kepada sesuatu, tetapi juga dapat dikatakan sebagai sikap subyek atas dasar adanya kebutuhan dan keingin tahuan untuk memenuhi kebutuhan. Menurut Ferdhy Febrian, ada 3 hal mendasar mengapa konsumen ingin membeli produk atau jasa yang ditawarkan

a. Faktor minat beli primer (kebutuhan barang pokok). Kebutuhan utama yang harus dipenuhi untuk bertahan hidup oleh calon pelanggan. Contoh : bahan makanan pokok (beras, gula, lauk pauk)

b. Faktor minat beli sekunder (kebutuhan pelengkap). Kebutuhan pelengkap dan hanya digunakan sesekali oleh calon pelanggan. Contoh : pakaian

c. Faktor minat beli tersier (kebutuhan spesifik). Kebutuhan yang dianggap tidak terlalu penting oleh calon pelanggan. Produk ini mempunyai 
spesifikasi khusus dengan pangsa pasar khusus.

\subsection{Kerangka Pikir}

Kerangka pikir penelitian merupakan penjelasan sementara terhadap gejala-gejala yang menjadi objek permasalahan dalam penelitian, dengan kerangka pemikiran dapat diketahui alur pemikiran peneliti yang tujuannya adalah untuk menguji harga dan kualitas produk terhadap minat beli PT. Tunas Motor Pratama.

\subsection{Hipotesis Penelitian}

Hipotesis adalah penjelasan sementara tentang perilaku, fenomena atau keadaan tertentu yang telah terjadi atau akan terjadi, yang kemudian akan diuji kebenarannya melalui penelitian yang dilakukan (Kuncoro, 2005:48). Berdasarkan latar belakang masalah, perumusan masalah dan kerangka konseptual, maka hipotesis yang dikemukakan oleh peneliti yaitu :

1. Kualitas produk (X1) berpengaruh positif dan signifikan terhadap minat beli konsumen pada PT. Tunas Motor Pratama.

2. Harga (X2) berpengaruh positif dan signifikan terhadap minat beli konsumen pada PT. Tunas Motor Pratama.

3. Promosi (X3) berpengaruh positif dan signifikan terhadap minat beli konsumen pada PT. Tunas Motor Pratama.

\section{METODE PENELITIAN}

\subsection{Model Penelitian}

Penelitian ini dilakukan dengan tujuan untuk mengetahui pengaruh kualitas produk dan promosi terhadap keputusan pembelian dengan minat beli sebagai variabel intervening, dan sumber tersebut dari konsumen yang melakukan pembelian motor Honda di PT. Tunas Motor Pratama. Bentuk pengamatan yang dilakukan dalam penelitian ini adalah bentuk survei. Survei dilakukan untuk memperoleh fakta-fakta dari gejala yang ada dan mencari secara faktual, dalam penelitian ini data dikumpulkan dari responden dengan menggunakan kuesioner. Data yang digunakan dalam penelitian ini adalah data primer.

\subsection{Operasional Variabel Penelitian}

Variabel penelitian adalah subjek penelitian atau apa yang menjadi titik perhatian suatu penelitian (Arikunto, 2006). Variabel yang diteliti harus sesuai dengan permasalahan dan tujuan yang ingin dicapai dalam penelitian, yang menjadi variabel dalam penelitian ini adalah :

\subsubsection{Variabel Independen}

1. Kualitas Produk (X1)

Kualitas produk yaitu kemampuan produk untuk menjalankan tugasnya yang mencakup daya tahan, kehandalan, kemajuan, kekuatan, kemudahan dalam pengemasan, dan reparasi produk dan ciri-ciri lainnya (Kotler dan Armstrong, 1997).

2. Harga (X2)

Harga adalah sejumlah uang yang ditukarkan untuk sebuah produk atau jasa (Kotler dan Amstrong, 2001).

3. Promosi (X3)

Promosi adalah suatu bentuk komunikasi pemasaran, yang merupakan aktivitas pemasaran yang berusaha menyebarkan informasi, mempengaruhi, membujuk, dan mengingatkan pasar sasaran atas perusahaan dan produknya agar bersedia menerima, membeli, dan loyal pada produk yang ditawarkan perusahaan yang bersangkutan.

\subsubsection{Variabel Dependen}

Variabel dependen merupakan variabel yang menjadi pusat perhatian peneliti (Ferdinand, 2006). Variabel dependen adalah variabel yang nilainya tergantung pada variabel lain, dimana nilainya akan 
berubah jika variabel yang mempengaruhinya berubah. Variabel dependen $(\mathrm{Y})$ pada penelitian ini adalah keputusan pembelian.

\subsubsection{Variabel Intervening}

Menurut Keller (1998) minat konsumen adalah seberapa besar kemungkinan konsumen membeli suatu merek atau seberapa besar kemungkinan konsumen untuk berpindah dari satu merek ke merek lainnya. Schiffman dan Kanuk (2007) dalam Febiana (2014) menyatakan bahwa minat merupakan salah satu aspek psikologis yang memiliki pengaruh cukup besar terhadap sikap perilaku. Penilaian konsumen terhadap produk tergantung pada pengetahuannya akan informasi tentang fungsi sebenarnya dari produk tersebut, dengan demikian konsumen yang berminat untuk melakukan pembelian suatu produk dipengaruhi oleh informasi yang diterima.

\subsection{Populasi dan Sampel}

\subsubsection{Populasi}

Menurut Sugiyono (2014) populasi adalah wilayah generalisasi yang terdiri atas obyek atau subjek yang memiliki karakteristik tertentu yang kemudian ditetapkan oleh peneliti untuk dipelajari dan ditarik kesimpulanya. Populasi yang digunakan dalam penelitian ini adalah seluruh konsumen yang melakukan pembelian di PT. Tunas Motor Pratama, dengan jumlah populasi tidak diketahui dengan pasti.

\subsubsection{Sampel}

Sampel adalah jumlah elemen yang dimasukan dalam sampel, besarnya sampel sangat dipengaruhi banyak faktor antara lain tujuan penelitian, bila penelitian bersifat deskriptif maka umumnya membutuhkan sampel yang besar tetapi bila penelitianya hanya untuk menguji hipotesis, dibutuhkan sampel dalam jumlah yang lebih sedikit (Ferdinand, 2011).

\subsection{Teknik Pengumpulan Data}

Metode pengumpulan data yang digunakan dalam penelitian ini adalah sebagai berikut :

a. Kuesioner atau Angket

Kuesioner atau angket adalah teknik pengumpulan data yang dilakukan dengan cara memberi pertanyaan tertulis kepada responden dan kemudian dijawab (Dajan, 1986). Metode kuesioner (questionnaire) adalah daftar pertanyaan yang mencakup semua pernyataan dan pertanyaan yang akan digunakan untuk mendapatkan data, baik yang dilakukan melalui telepon, surat atau bertatap muka (Ferdinand, 2011). Dalam menjawab pertanyaan, penelitian ini menggunakan skala likert. Menurut Sugiyono, (2011) skala likert digunakan untuk mengukur sikap, pendapat, dan persepsi orang atau sekelompok orang tentang fenomena sosial. Dengan skala likert, maka variabel yang akan diukur dijabarkan menjadi indikator variabel. Dalam skala likert setiap instrumen mempunyai gradasi.

\subsection{Teknik Analisis Data}

Metode analisis data merupakan salah satu cara yang digunakan untuk mengetahui sejauh mana variabel yang mempengaruhi variabel lain agar data yang dikumpulkan tersebut dapat bermanfaat maka harus dianalisis terlebih dahulu sehingga dapat dijadikan pertimbangan dan pengambilan keputusan. Analisis dilakukan untuk mempermudah bagi pengguna data untuk memahami makna dari data tersebut sehingga dapat menintepretasikannya sesuai dengan data yang telah dianalisis tersebut.

\subsubsection{Uji Asumsi Klasik}

Uji asumsi Klasik dilakukan sebelum pengujian regresi dilakukan. Pengujian ini untuk memastikan bahwa data akan 
memberikan hasil yang BLUE (Best Linier Unblased Estimator). Uji asumsi klasik yang dilakukan dalam penelitian ini adalah uji normalitas, uji multikolinearitas, dan uji heteroskedastisitas (Ghozali, 2011).

\subsubsection{Uji Normalitas}

Menurut Ghozali (2011) uji normalitas bertujuan untuk mengetahui apakah dalam model regresi, variabel terikat dan variabel bebas memiliki distribusi yang normal atau mendekati normal. Pembuktian apakah data tersebut memiliki distribusi normal atau tidak dapat dilihat pada bentuk distribusi datanya. Ada dua kriteria yang dapat digunakan dalam uji normalitas yaitu meliputi :

1. Analisis Grafik dan Kurva Probability plot (P-Plot) Distribusi normal jika data berbentuk garis lurus mendekati diagonal yang dapat dilihat penyebaran data (titik) pada sumbu diagonal.

2. Analisis Statistik Kolmogorov-Simirnov Analisis Statistik non parametik Kolmogorov-Simirnov (K-S), Uji K-S dilakukan dengan menghitung residual data distribusi normal. Suatu data dikatakan normal jika besarnya nilai dari $\mathrm{K}-\mathrm{S}>\alpha=0,05$. Ghozali (2011) menyebutkan jika data menyebar disekitar garis diagonal dan mengikuti arah garis diagonal maka model regresi memenuhi asumsi normalitas.

\subsubsection{Uji Multikolinearitas}

Menurut Ghozali (2011:105), multikolinearitas bertujuan untuk menguji apakah model regresi ditemukan adanya korelasi antar variabel bebas (independen). Untuk mendeteksi ada atau tidaknya multikolinearitas didalam model regresi adalah sebagai berikut :

1. Nilai R2 yang dihasilkan oleh suatu estimasi model regresi empiris sangat tinggi, tetapi secara individual veriabelvariabel independen banyak yang tidak signifikan mempengaruhi variabel dependen.

2. Menganalisis matrik korelasi variabelvariabel independen. Jika antar variabel independen ada korelasi yang cukup tinggi (umumnya diatas 0.90) maka hal ini merupakan indikasi adanya multikolinearitas.

3. Multikolinearitas dapat juga dilihat dari nilai tolerance dan variance inflation model (VIF). Nilai tolerance yang rendah sama dengan nilai VIF tinggi (karena VIF = 1/Tolerance). Nilai cutoff yang umum dipakai untuk menunjukan adanya multikolinearitas adalah nilai tolerance $\leq 0.10$ atau sama dengan nilai $\mathrm{VIF} \geq 10$.

\subsubsection{Uji Heteroskedastisitas}

Menurut Ghozali (2011), uji heteroskedastisitas bertujuan untuk mengetahui apakah dalam model regresi terjadi ketidaksamaan variance dari residual satu pengamatan ke pengamatan yang lain. Jika variance dari residual satu pengamatan kepengamatan yang lain tetap maka disebut homokedastisitas, namun jika berbeda disebut heteroskedastisitas. Model regresi yang baik adalah homokedastisitas atau tidak terjadi heteroskedastisitas. Deteksi heteroskedastisitas dilakukan dengan menggunakan cara berikut :

\section{Analisis Grafik Scatter Plot}

Model regresi yang baik dapat dilihat dari persebaran pola titik titik yang menyebar, jika titik-titik di Scatter plot menyebar maka tidak terjadi heteroskedastisitas.

\section{Analisis Statistik Gletser}

Diteksi secara statistik gletser dapat menunjukan nilai signifikansi absolut masing masing variabel. Jika probabilitas signifikan > $5 \%$ maka dapat dinyatakan bahwa model regresi tidak terjadi heteroskedastisitas. Salah satu cara untuk mendeteksi ada atau tidaknya 
heteroskedastisitas adalah dengan melihat grafik plot antar prediksi variabel dependen (ZPRED) dengan residualnya (SRESID). Deteksi ada tidaknya heteroskedastisitas dapat dilakukan dengan melihat ada tidaknya pola titik pada grafik scatterplot antara SRESID dan ZPRED, dimana sumbu $\mathrm{Y}$ adalah $\mathrm{Y}$ yang telah diprediksi dan sumbu $\mathrm{X}$ adalah residual yang telah distandarized (Ghozali, 2011).

\subsection{Uji Hipotesis}

\subsubsection{Uji Parametrik Individu (Uji-t)}

Uji hipotesis dilakukan dengan uji signifikan parameter individual (uji statistik t) uji statistik t pada dasarnya menunjukan seberapa jauh pengaruh satu variabel penjelas atau independen secara individual dalam menerangkan variasi variabel dependen. Hipotesis nol (Ho) yang hendak diuji adalah apakah suatu parameter (bi) sama dengan nol, atau :

Ho : bi=0

Artinya apakah suatu variabel independen bukan merupakan penjelas yang signifikan terhadap variabel dependen. Hipotesis alternatifnya (Ha) parameter suatu variabel tidak sama dengan nol, atau :

$\mathrm{Ha}: \mathrm{bi} \neq 0$

Artinya variabel tersebut merupakan penjelas yang signifikan terhadap variabel dependen (Ghozali, 2011).

Dasar pengambilan keputusan adalah dengan menggunakan angka probabilitas signifikan $=0,05$, yaitu :

1. Jika $\mathrm{t}$ hitung $>\mathrm{t}$ tabel, dan sig. hitung < Sig. tabel dengan angka probabilitas signifikansi $=0,05$ maka Ho ditolak dan $\mathrm{Ha}$ diterima.

2. Jika t hitung $<\mathrm{t}$ tabel, dan sig. Hitung $>$ Sig. tabel dengan angka probabilitas signifikansi $=0,05$ maka Ho diterima dan Ha ditolak.

\section{HASIL PENELITIAN DAN PEMBAHASAN \\ 4.1. Deskripsi Data}

Sejarah dealer Tunas Motor Pratama berdiri pada tahum 01 Juni 1979, dan dealer ini termasuk yang tertua di Bandar lampung. Tunas Motor Pratama terletak di Jalan Ikan Tenggiri No.49, Teluk Betung Bandar Lampung. Owner Tunas Motor Pratama ialah Djoko Wiryawan Sutanto, Tunas Motor Pratama memiliki 20 karyawan yang terdiri dari PIC (Person In Charge), staf administrasi, kepala sales, sales, ADH, kasir, mekanik. Para karyawan bekerja sama sebaik mungkin dalam melayani konsumen. PIC bertugas untuk mengkordinasikan pekerjaan teknisi dan kepala sales bertugas untuk mengkoordinasikan sales dan kasir. Sales melayani konsumen untuk memilih motor yang sesuai dengan kebutuhan dan selera mereka. Sales di Tunas Motor Pratama sangat ramah dan selalu berusaha memberikan pelayanan yang terbaik kepada konsumen. Tunas Motor Pratama memiliki mekanik yang kompeten di bidangnya, dan kasir bertugas untuk menerima pembayaran dari konsumen yang membeli motor atau service kendaraan mereka. Staf administrasi bertugas untuk menyiapkan segala kebutuhan operasional di Tunas Motor Pratama, membuat surat surat penawaran bila dibutuhkan, menyiapkan dokumen dokumen yang dibutuhkan, merekap penjualan sales. Selain itu staf administrasi bertanggung jawab untuk memberikan laporan kinerja sales kepada PIC (Person In Charge). Sementara itu PIC selalu stanby untuk membantu dan mengatasi masalah masalah yang tidak dapat ditangain oleh sales, dan staf administrasi. PIC (Person In Charge). 


\subsection{Analisis data}

Variables Entered/Removed $^{\mathrm{a}}$

\begin{tabular}{|c|c|c|c|}
\hline Model & Variables Entered & Variables Removed & Method \\
\hline 7 & $\mathrm{X} 2, \mathrm{X} 1^{\mathrm{b}}$ & & Enter \\
\hline
\end{tabular}

b. All requested variables entered.

Model Summary ${ }^{\mathrm{b}}$

\begin{tabular}{lr|r|r|r} 
& & & \\
Model & $\mathrm{R}$ & $\mathrm{R}$ Square & $\begin{array}{c}\text { Adjusted R } \\
\text { Square }\end{array}$ & $\begin{array}{c}\text { Std. Error of } \\
\text { the Estimate }\end{array}$ \\
\hline 1 &, $863^{\mathrm{a}}$ &, 745 &, 715 & 3,27399 \\
\hline
\end{tabular}

b. Dependent Variable: Y

ANOVA $^{\mathrm{a}}$

\begin{tabular}{|c|c|c|c|c|c|c|}
\hline \multicolumn{2}{|c|}{ Model } & $\begin{array}{l}\text { Sum of } \\
\text { Squares }\end{array}$ & df & $\begin{array}{c}\text { Mean } \\
\text { Square }\end{array}$ & $\mathrm{F}$ & Sig. \\
\hline \multirow[t]{3}{*}{1} & Regression & 533,527 & $\overline{2}$ & 266,763 & 24,887 &, $000^{6}$ \\
\hline & Residual & 182,223 & 17 & 10,719 & & \\
\hline & Total & 715,750 & 19 & & & \\
\hline
\end{tabular}

a. Dependent Variable: Y

b. Predictors: (Constant), X2, X1

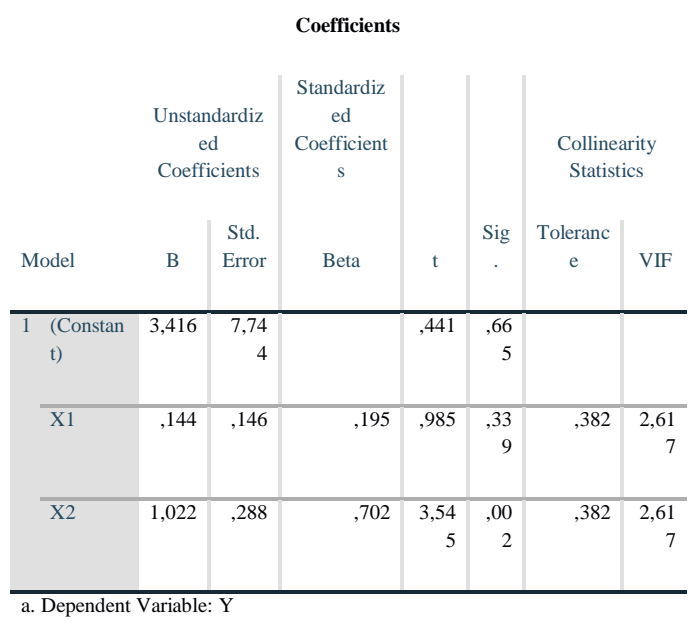

Collinearity Diagnostics $^{\mathrm{a}}$

\begin{tabular}{|c|c|c|c|c|c|c|}
\hline \multirow[b]{2}{*}{ Model } & \multirow[b]{2}{*}{ Dimension } & \multirow[b]{2}{*}{ Eigenvalue } & \multirow{2}{*}{$\begin{array}{c}\text { Condition } \\
\text { Index }\end{array}$} & \multicolumn{3}{|c|}{ Variance Proportions } \\
\hline & & & & (Constant) & $\mathrm{X} 1$ & $\mathrm{X} 2$ \\
\hline \multirow[t]{3}{*}{1} & $\overline{1}$ & 2,990 & 1,000 &, 00 & $\overline{, 00}$ & $\overline{, 00}$ \\
\hline & 2 & ,007 & 19,985 &, 71 & ,01 & ,28 \\
\hline & 3 & ,002 & 36,711 & ,29 &, 99 &, 72 \\
\hline
\end{tabular}

\section{Residuals Statistics}

\begin{tabular}{|c|c|c|c|c|c|}
\hline & Minimum & Maximum & Mean & $\begin{array}{c}\text { Std. } \\
\text { Deviation }\end{array}$ & $\mathrm{N}$ \\
\hline $\begin{array}{l}\text { Predicted } \\
\text { Value }\end{array}$ & 41,5091 & 62,1774 & 50,2500 & 5,29909 & 20 \\
\hline $\begin{array}{l}\text { Std. } \\
\text { Predicted } \\
\text { Value }\end{array}$ & $-1,650$ & 2,251 & ,000 & 1,000 & 20 \\
\hline $\begin{array}{l}\text { Standard } \\
\text { Error of } \\
\text { Predicted } \\
\text { Value }\end{array}$ & ,764 & 2,045 & 1,216 & ,369 & 20 \\
\hline $\begin{array}{l}\text { Adjusted } \\
\text { Predicted } \\
\text { Value }\end{array}$ & 40,8222 & 60,8362 & 50,1212 & 5,35925 & 20 \\
\hline Residual & $-6,84324$ & 4,11428 & ,00000 & 3,09689 & 20 \\
\hline $\begin{array}{l}\text { Std. } \\
\text { Residual }\end{array}$ & $-2,090$ & 1,257 & ,000 & 946 & 20 \\
\hline $\begin{array}{l}\text { Stud. } \\
\text { Residual }\end{array}$ & $-2,150$ & 1,473 & ,017 & 1,029 & 20 \\
\hline $\begin{array}{l}\text { Deleted } \\
\text { Residual }\end{array}$ & $-7,24310$ & 6,17779 & , 12876 & 3,70220 & 20 \\
\hline $\begin{array}{l}\text { Stud. } \\
\text { Deleted } \\
\text { Residual }\end{array}$ & $-2,445$ & 1,530 & ,008 & 1,073 & 20 \\
\hline $\begin{array}{l}\text { Mahal. } \\
\text { Distance }\end{array}$ & ,085 & 6,466 & 1,900 & 1,769 & 20 \\
\hline $\begin{array}{l}\text { Cook's } \\
\text { Distance }\end{array}$ & ,000 & ,463 &, 070 & , 104 & 20 \\
\hline $\begin{array}{l}\text { Centered } \\
\text { Leverage } \\
\text { Value }\end{array}$ & ,004 & 340 & , 100 & ,093 & 20 \\
\hline
\end{tabular}




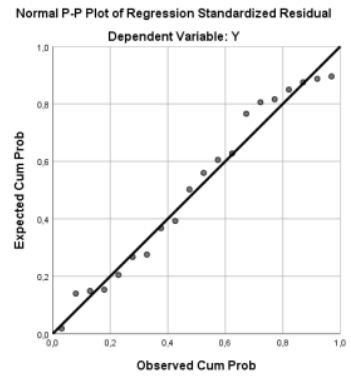

\subsection{Pembahasan}

Bagian ini mengkaji hasil penelitian untuk menjawab rumusan masalah mengenai model keputusan pembelian dengan memunculkan variabel intervening minat beli, pembahasan ini diawali dengan pembahasan hasil pengujian hipotesis yang dilakukan dalam penelitian ini. Pembahasan hasil pengujian hipotesis dijelaskan dengan mengungkapkan fakta empiris serta relevasinya dengan teori dan hasil penelitian sebelumnya. Dalam penelitian ini menggunakan Theory of Reasoned Action (TRA). Menurut Arnould (2005) Theory of Reasoned Action (TRA) adalah teori yang memiliki asumsi bahwa konsumen secara sadar mempertimbangkan dan memilih salah satu dari pertimbangan tersebut yang dapat memberikan konsekuensi paling diharapkan. Ajzen dalam Dharmmesta (1998) menyatakan bahwa kontrol keperilakuan yang dirasakan dapat berpengaruh pada minat atau secara langsung pada perilaku itu sendiri. Model yang sudah dimodifikasi tersebut kemudian dikenal dengan Theory of Planned Behavior.

\section{KESIMPULAN DAN SARAN}

\subsection{Kesimpulan}

Berdasarkan hipotesis yang diajukan dalam penelitian ini maka dapat disimpulkan bahwa:

1. Produk (X1) berpengaruh secara positif dan signifikan terhadap kepuasan konsumen. Jika garansi produk baik, kualitas produk baik dan produk yang dijual lengkap/beragam maka kepuasan konsumen akan naik dan sebaliknya.

2. Harga (X2) berpengaruh secara positif namun tidak signifikan terhadap kepuasan konsumen. Jika harga semakin bersaing, ada pemberian potongan harga kepada konsumen, dan harga sesuai dengan kualitas produk yang dijual maka kepuasan konsumen semakin meningkat dan sebaliknya.

3. Promosi (X3) berpengaruh terhadap minat beli. Hal ini berarti promosi yang telah dilakukan berpengaruh terhadap konsumen untuk meningkatkan minat beli. Jika promosi yang dilakukan produsen terarah maka akan meningkatkan minat beli.

\subsection{Saran}

Berdasarkan kesimpulan dalam penelitian ini maka dapat diberikan saran sebagai berikut:

1. PT. Tunas Motor Pratama perlu menjaga dan meningkatkan kualitas produk yang dijual, menyediakan motor dengan merk dan spesifikasi yang beragam dan memberikan garansi terhadap setiap produk yang dijual.

2. PT. Tunas Motor Pratama perlu menawarkan harga yang bersaing dan memberikan potongan harga terhadap motor yang dijual dan harga yang ditawarkan harus sesuai dengan kualitas produk yang dijual.

3. PT. Tunas Motor Pratama perlu membuat iklan yang menarik perhatian konsumen baik melalui papan reklame, iklan radio, iklan koran yang menarik maupun melalui media sosial seperti facebook dan instagram 
4. PT. Tunas Motor Pratama perlu meningkatkan pengetahuan wawasan karyawannya, melayani konsumen dengan ramah, sigap, cepat tanggap dan bersedia membantu konsumen ketika menemukan masalah.

5. PT. Tunas Motor Pratama perlu memperluas lahan parkir kendaraan untuk kenyamanan konsumen.

\section{DAFTAR PUSTAKA}

Amstrong, Kottler., (1997), "PrinsipPrinsip Pemasaran”, Erlangga, Jakarta

Anto Dajan, 1986, Pengantar Metode Statistik II, Penerbit LP3ES, Jakarta

Augusty, Ferdinand. 2006. Metode Penelitian Manajemen: Pedoman Penelitian untuk skripsi, Tesis dan Disertai Ilmu Manajemen. Semarang: Universitas Diponegoro

Augusty Ferdinand. 2011, Metode Penelitian Manajemen Pedoman Penelitian untuk Penulisan Skripsi, Tesis, dan Disertasi Ilmu Manajemen, Edisi 3, AGF Books, Fakultas Ekonomika dan Bisnis Universitas Diponegoro, Semarang

Arikunto, Suharsimi. 2006. Prosedur Penelitian Untuk Suatu Pendekatan Praktik. Jakarta : Rineka Cipta

Arikunto, Suharsimi. 2014. Prosedur Penelitian Suatu Pendekatan Praktik. Jakarta : Rineka Cipta.

Bimo Walgito. 2002. Pengantar Psikologi Umum. Yogyakarta: Andi Offset

Ferdhy Febrian, The Power of Selling, Jakarta: Elex Media Komputindo, 2010
Ghozali, Imam. 2011. "Aplikasi Analisis Multivariate Dengan Program SPSS". Semarang: Badan Penerbit Universitas Diponegoro.

Keller, Kevin Lane. 1998. Strategic Brand Management: Building, Measuring, and Managing Brand Equity. New Jersey: Prentice-Hall, Inc

Kotler, Amstrong. 2001. Prinsip-prinsip pemasaran, Edisi keduabelas, Jilid 1. Jakarta: Erlangga

Mudrajad, Kuncoro. 2005. Strategi Bagaimana Meraih Keunggulan Kompetitif. Erlangga. Jakarta

Sukardi, Dewa Ketut. 2002.Pengantar Pelaksanaan Program Bimbingan dan Konseling di Sekolah. Jakarta: Rineka Cipta.

Schiffman, L.G. dan L.L. Kanuk. 2007. Consumer Behavior. New Jersey: Prentice Hall.

Sugiyono. 2011. Metode Penelitian Kuantitatif, Kualitatif dan R\&D. Bandung: Afabeta

Sugiyono. (2014). Metode Penelitian Pendidikan Pendekatan Kuantitatif, Kualitatif, dan R\&D. Bandung: Alfabeta 